\title{
Impact of rail impedance intrinsic variability on railway system operation, EMC and safety
}

\author{
Andrea Mariscotti \\ Department of Electrical, Electronic and Telecommunications Engineering, and Naval Architecture (DITEN), \\ University of Genova, Italy
}

\begin{tabular}{|c|c|}
\hline Article Info & ABSTRACT \\
\hline Article history: & Running rails in electrified transportation systems are the interface element \\
\hline Received Nov 2, 2019 & $\begin{array}{l}\text { for several phenomena related to system performance, electromagnetic } \\
\text { compatibility and safety: useful voltage at rolling stock, short circuit current, }\end{array}$ \\
\hline Revised Jun 11, 2020 & induced voltage, stray current, and track circuit operation. This work \\
\hline Accepted Jul 30, 2020 & $\begin{array}{l}\text { presents the physical and mathematical groundings of rail electrical } \\
\text { parameters (DC and AC resistance, AC internal and external inductance) and }\end{array}$ \\
\hline Keywords: & $\begin{array}{l}\text { experimental results available in the literature, discussing variability and } \\
\text { reliability for each interface. The results consist thus of the identification of }\end{array}$ \\
\hline Induced voltage & the relevant rails longitudinal electrical parameters, the presentation of a set \\
\hline Inductance & $\begin{array}{l}\text { of reliable experimental values, and the discussion of the best approach to } \\
\text { manage their variability and uncertainty. }\end{array}$ \\
\hline Resistance & \\
\hline
\end{tabular}

Running rails

Stray current

Track circuits

This is an open access article under the CC BY-SA license.

\section{Corresponding Author:}

Andrea Mariscotti,

Department of Electrical, Electronic and Telecommunications Engineering, and Naval Architecture,

University of Genova,

Via Opera Pia, 11A - 16145, Genova, Italy.

Email: andrea.mariscotti@unige.it

\section{INTRODUCTION}

Running rails are one of the key interface elements in an electric transportation system: they are the main element of the return circuit and affect the useful voltage value [1] available at the catenary (or third rail) rolling stock interface; as part of the return circuit they are a relevant impedance term to consider for the short-circuit current estimate [2-4] and they contribute to reduce the induction caused by the catenary current $[5,6]$; they are also unfortunately the coupling means of stray current onto the track fastening system, the rest of the infrastructure and third parties [6-11]; finally, they allow the detection of passing trains by means of track circuits [12-19].

Being the running rails first of all a mechanical element with the primary function of supporting and guiding the rolling stock, accurate assessment of their electric behavior is always in the background. This is stigmatized by the lack of standardization for acceptable or limit values, the poor coverage in manufacturers' datasheets (that rarely report the DC resistance, not to say the temperature dependency or the internal impedance), and a general shortage of technical specifications and literature references, that would be a valuable input to design. Having observed a lack of accurate determination and documentation of rail electric parameters and substantial variability of values coming from different sources, this work reports a synthesis of the available published data and discusses their relevance for the five discussed electrical interfaces: i) useful voltage and train performance, ii) short-circuit current estimate, iii) induction on conductive parts, iv) stray current leakage, and v) track circuit operation and tuning. 
From a high-level viewpoint these interfaces can be classified as impacting on system operation and performance (i), on electrical safety (ii, iii), on functional safety (iii, v), on structural safety and impact on third parties (iv) and on electromagnetic compatibility (iii). Interfaces are then evaluated using more or less complex models fed among others by the rail electric parameters [20], including variability in a final compliance statement: validation of simulation models based on experimental data can be found in [21], where rail resistance and its variability are explicitly accounted for. Another example of tuning a model to fit experimental results is described in [22, 23], where AC rail impedance is evaluated to predict network response to electric arc phenomena.

\section{RAIL RESISTANCE AND RAIL IMPEDANCE}

For running rails, we may distinguish between $\mathrm{DC}$ and $\mathrm{AC}$ parameters, the latter divided into internal and external ones, or self and mutual, if the rest of the line is considered [23]. Excluding mutual terms, the overall rail self-impedance considered in the following is made of a geometric part (also named external) and an intrinsic part (the internal impedance). Both external terms for the self $\left(Z_{i i, e x t}\right)$ and the mutual $\left(Z_{i j, e x t}\right)$ impedance can be calculated with good accuracy using known formulas, such as Carson's ones $[5,23]$.

$$
Z_{i i, e x t}=j \omega \frac{\mu_{0}}{2 \pi} \ln \frac{2 h_{i}}{r_{i}}+2\left(\Delta R_{i i}+j \Delta X_{i i}\right) \quad Z_{i j, e x t}=j \omega \frac{\mu_{0}}{2 \pi} \ln \frac{D_{i j}}{d_{i j}}+2\left(\Delta R_{i j}+j \Delta X_{i j}\right)
$$

where: $d_{i j}$ is the distance between conductors $i$ and $j ; D_{i j}$ is the distance between conductor $i$ and image of conductor $j$, and vice versa; $h_{i}$ is the height above ground of conductor $i ; r_{i}$ is the radius of conductor $i$. The $\Delta R$ and $\Delta X$ terms are corrective terms for the effect of soil appearing in [12], page 162, and [24]. Although these equations may lead to some variability due to approximations of geometric terms and secondary effects, such as proximity, they are considered accurate and most of all "inspectionable", where calculations can be verified and repeated at will, including sensitivity analysis [25, 26]. Attention is conversely focused on the intrinsic parameters specific to the rail that as we will see cannot rely on modeling for an accurate quantification; they are the DC resistance, the AC resistance and internal inductance [24, 27-34].

For the combination of self and mutual terms for each of the running rails to form the track impedance we may distinguish two cases: an electric parallel of the two running rails for almost all traction purposes (possibly backed up by other parallel additional conductors forming the return circuit [23, 35]) and a differential connection of the rails for track-circuit signaling applications [36, 37]. Internal rail parameters are not involved in the magnetic coupling between the two rails, for which they are in simple electric parallel in the first case and in series in the second, with common-mode and differential-mode transfer functions for the track mainly determined by the track geometry and coupling to earth [12], sec. II.D, [36]. It is briefly observed that the parameters that influence the differential mode circuit of the track to effectively model track response for signaling purposes must be supplemented by a representation of rail-to-rail and rail-toground capacitance (theoretically calculable, but necessitating correction for the non-circular rail shape and the presence of ground $[37,38]$ ) and conductance (largely influenced by practical factors and by the mixed surface and volume conductivity and consequential leakage [39-41]. These aspects are however outside the scope of this work that focuses on the longitudinal rail parameters. In the following subsections the available experimental results are reviewed for DC resistance and AC impedance, namely resistance and inductance.

\subsection{DC rail resistance}

Despite the intuitive nature of the rail DC resistance and its relevance, there are no clear requirements for its determination and characterization (e.g. accuracy, temperature of measurement, variability of samples). On this it is symptomatic that the EN 13674-1 standard for running rails [42] never mentions the word "resistance". Rail DC resistance influences directly the voltage drop in the return circuit (and thus useful voltage and train performance), as well as stray current leakage:

- The rail voltage drop in DC systems is a direct consequence of the achieved track longitudinal resistance by means of minimization of rail resistance, welding and joints effect, and track-to-track bonding, with optional parallel feeding;

- The amount of stray current leaving the rails and the efficiency of the stray current drainage see the rail resistance as a very important parameter [7, 9, 11]; assessment during design and construction phases should be based on reliable rail resistance values. 
DC rail resistance values are shown in Table 1 based on [43-47]. For the temperature coefficient Kiesslieng et al. [43] strangely report two different values of $0.47 \% /{ }^{\circ} \mathrm{C}$ and $0.6 \% /{ }^{\circ} \mathrm{C}$ for the same steel running rails in the same paragraph. Kolar et al. [44], however, report a similar intermediate value of $0.5 \% /{ }^{\circ} \mathrm{C}$. For AC rail resistance the temperature coefficient is slightly lower $\left(0.3 \% /{ }^{\circ} \mathrm{C}\right)$ and will be considered later. Despite the relatively large temperature coefficient, values of DC resistance are seldom accompanied by the information on the rail temperature and other test conditions, so that they must all be deemed inaccurate at $\pm 5 \%$, corresponding to a rail temperature between e.g. 20 and $40{ }^{\circ} \mathrm{C}$. Agreement between selected measured values for the same type of rail is approximately of the same order: S49 values differ by $2.8 \%$ with respect to their average, UNI60 values by $2.9 \%$ and R65 values up to $4.4 \%$.

It is observed that welding of rail segments is allowed to add another $5 \%$ of longitudinal resistance (EN 50122-2, sec. 6.2.2 [48]). Fishplates may be responsible for additional resistance in the order of $300-350 \mu \Omega$, equivalent to about $10 \mathrm{~m}$ of rail (ref. internal report).

Table 1. DC resistance values

\begin{tabular}{cccc}
\hline Rail type & Rail weight $[\mathrm{kg} / \mathrm{m}]$ & DC resistance $[\mathrm{m} \Omega / \mathrm{km}] @$ temp. of meas. & Reference \\
\hline DO 350 & 60 & $33.5 @ 30^{\circ} \mathrm{C}$ & internal report \\
DO 260 & 60 & $30.6 @ 39^{\circ} \mathrm{C}$ & internal report \\
Evraz 60E1, R350 & 60 & $37.8 @ 32^{\circ} \mathrm{C}$ & internal report \\
Evraz 60E1, R260 & 60 & $32.0 @ 31^{\circ} \mathrm{C}$ & {$[43]$} \\
Generic S49 & 49.4 & 35.7 & {$[43]$} \\
Generic R50 & 50.5 & 34.5 & {$[43]$} \\
Generic S54 & 54.5 & 32.0 & {$[43]$} \\
Generic UIC54 & 54.4 & 32.0 & {$[43]$} \\
Generic S60 & 60.3 & 28.9 & {$[43]$} \\
Generic UIC60 & 60.3 & 28.9 & {$[43]$} \\
Generic R65 & 65.1 & 25.2 & {$[44]$} \\
Generic UIC60 & - & 32.5 & {$[44]$} \\
Generic R65 & - & 30.1 & {$[44]$} \\
Generic S49 & - & 40.0 & {$[45]$} \\
Sumitomo DHH340 & - & 22.8 & {$[45]$} \\
Sumitomo DHH370 & - & 23.4 & {$[46]$} \\
Generic 60E1 & $(1)$ & $34.9^{(3)}$ & {$[47]$} \\
Generic $^{(2)}$ & 60.2 & 43.8 & {$[47]$} \\
Generic $^{(2)}$ & 45 & 38.6 & {$[47]$} \\
Generic $^{(2)}$ & 53 & 33.0 & report \\
\hline
\end{tabular}

(1) Six different resistivity values measured along the rail cross section $\left(2.57,2.58,2.62,2.7,2.75,2.8510^{-7} \Omega / \mathrm{m}\right)$, giving an average DC rail resistance of $34.9 \mathrm{~m} \Omega / \mathrm{km}$;

(2) Not clear if measured values, no reference temperature;

${ }^{(3)}$ Average value out of six sampled internal resistivity values.

\subsection{AC rail resistance}

The rail AC resistance (real part of the self impedance term shown in (1)), compared to the DC counterpart, is much less relevant for voltage drop and short circuit calculations, being in series to a much larger rail inductive reactance (imaginary part of the self impedance in (1)), to form the loop impedance of the return circuit (that thus accounts for the impedance of the catenary and the mutual impedance with the return circuit). However, the change of $\mathrm{AC}$ resistance with the amplitude and frequency of the flowing current is peculiar (and to add its temperature dependency): it is caused by the skin effect and change of magnetic permeability, that for small signal analysis must be considered as the local relative permeability of the hysteresis cycle developing around the bias point [24, 28, 34, 49-54], going from power to audiofrequency. The significant increase of the AC resistance is interpreted as "additional AC rail losses", relevant e.g. for accurate modeling and tuning of track circuits [12]: the AC rail resistance in the $\mathrm{kHz}$ range may influence significantly the factor of merit of the resonant circuits used to model the track circuit and its coupling unit through S-bonds (whose equivalent resistance and proximity effect with the rail onto they are fastened are other two critical parameters). In general changes of AC resistance may influence also the time constant of the fault equivalent circuit, as we will see in section "Short circuit calculation and transient behavior". Table 2 is thus focused on power frequency values (at 50 or $60 \mathrm{~Hz}$ ) and higher frequency values, covering the operating frequency range of track circuits.

The AC rail resistance is a challenging parameter for modeling purposes: in general modeled values differ largely from the experimental ones [24], so that identifying reliable measured values is quite important. Experimental values in [24] appear only in sec. 5.3-5.5, actually referring to Holmstrom [33]: values of AC resistance are reported by Holmstrom focusing on a differential track signal model, so they are twice the rail 
AC resistance. The authors in [24] recognize in sec. 6 that two important elements are missing from the used finite element model, rail material non-linearity and hysteresis, that are known to account for the largest share of material losses, and thus of AC resistance (see discussion in [24] and time domain curves in [29]).

With measurements in time domain it is possible to follow the variability of AC resistance and inductance along the hysteresis cycles (Figure 9 of [29]): AC resistance and internal inductance have similar dispersion, but the former has a more chaotic distribution of points, with not an evident dependence on the instantaneous biasing current at power frequency. For the temperature coefficient, anticipated in the previous section, sources of information are much less than for the DC resistance: $0.3 \% /{ }^{\circ} \mathrm{C}[24,31,32]$, slightly lower than that for the DC rail resistance.

Table 2. AC resistance values of running rails

\begin{tabular}{|c|c|c|c|c|}
\hline \multirow[t]{2}{*}{ Rail type } & \multirow[t]{2}{*}{ Rail weight $[\mathrm{kg} / \mathrm{m}]$} & \multicolumn{2}{|r|}{ Measured AC Resistance $[\mathrm{m} \Omega / \mathrm{m}]$} & \multirow[t]{2}{*}{ Ref. } \\
\hline & & Freq. $[\mathrm{Hz}]$ & Value vs. Current & \\
\hline - & 56 & $10,25,50,60$ & $\begin{array}{c}0.04,0.065,0.098,0.103(50 \mathrm{~A}), 0.068,0.12,0.16,0.178(300 \mathrm{~A}) \\
0.115,0.18,0.255,0.29(700 \mathrm{~A})\end{array}$ & [3] \\
\hline - & - & 50 & $0.409(10 \mathrm{~A}), 0.573(400 \mathrm{~A}), 0.649(700 \mathrm{~A})$ & [24][33] \\
\hline - & - & 10000 & $0.049(10 \mathrm{~A})$ & [24][33] \\
\hline - & - & 25 & 0.09 (200A), 0.15 (400A), 0.18 (600A), 0.175 (900A) & [27][32] \\
\hline - & - & 40 & $0.125(200 \mathrm{~A}), 0.2(400 \mathrm{~A}), 0.23(600 \mathrm{~A}), 0.23(900 \mathrm{~A})$ & {$[27][32]$} \\
\hline - & - & 60 & $0.155(200 \mathrm{~A}), 0.24(400 \mathrm{~A}), 0.275(600 \mathrm{~A}), 0.275(900 \mathrm{~A})$ & [27][32] \\
\hline - & - & 50 & $0.09(200 \mathrm{~A}), 0.125(400 \mathrm{~A}), 0.18(600 \mathrm{~A}), 0.24(1000 \mathrm{~A})$ & {$[27]^{(1)}$} \\
\hline - & - & 50 & $0.13(200 \mathrm{~A}), 0.225(400 \mathrm{~A}), 0.26(600 \mathrm{~A})$ & {$[27][34]^{(2)}$} \\
\hline UNI60 & - & 50 & $0.18(200 \mathrm{~A}), 0.25(400 \mathrm{~A}), 0.285(600 \mathrm{~A}), 0.3(1000 \mathrm{~A})$ & {$[27][28]$} \\
\hline UNI60 & - & 3500 & $1.45 \pm 30 \%(200 \mathrm{~A} @ 50 \mathrm{~Hz})$ & [29] \\
\hline UNI60 & - & 20000 & 2.8 $\pm 42 \%$ (200 A @50 Hz) & [29] \\
\hline
\end{tabular}

(1) Smallest ORE values, refs [6] and [7] appearing in [18].

(2) Close agreement with largest ORE values.

\subsection{AC rail inductance}

Self and mutual inductive terms can be estimated rapidly by generally accepted formulations, mostly based on Carson's equations. More complex calculation methods exist based mainly on finite element methods, finite difference time domain and variants, as discussed in [51-53], hardly applicable to non-linear means, such as the ferromagnetic steel of running rails. A residual part due to secondary effects inside the running rail remains unexpressed: the internal inductance is caused by internal flux linkage within the rail surface and is heavily influenced by the varying magnetic permeability and skin effect, depending on the frequency and on the intensity of the flowing current, as well as on the proximity effect with other conductors (such as S-bond conductors [12] and including the adjacent rail forming the track). As pointed out in [54], different parts of the same rail sample may exhibit quite different electrical parameters due to different annealing and crystallization and varying mechanical stress during use. We may define the internal impedance as the ratio of the linear voltage drop along the rail surface and the total current in the conductor; the position for the measurement of this voltage drop was chosen by Trueblood and Wascheck [3, 32] on the rail head, as the farthest point on the rail periphery. The internal inductive reactance represents the imaginary part of the internal impedance; the AC rail resistance can be interpreted as the real part [24].

$$
Z_{\text {int }}=\frac{V_{s}}{I} \quad R_{\text {int }}=\operatorname{Re}\left\{Z_{\text {int }}\right\} \quad L_{\text {int }}=\operatorname{Im}\left\{Z_{\text {int }}\right\} / 2 \pi f
$$

The internal inductance is significant at low frequency [3]; its behavior is described in [3] as tending to a constant value above about $20 \mathrm{~Hz}$, with the magnetic flux linkage within the rail approaching a minimum; below the same $20 \mathrm{~Hz}$ internal inductance increases rapidly as the skin effect decreases, and dependence on current is more significant. Test methods and results are fully reported and discussed in [24, 28-34]. In particular, Holmstrom [33] reports linear regressions of measured internal inductance values for $100 \mathrm{lb} / \mathrm{yd}(49.6 \mathrm{~kg} / \mathrm{m})$ and $150 \mathrm{lb} / \mathrm{yd}(74.4 \mathrm{~kg} / \mathrm{m})$ rails, the latter showing a substantial dispersion versus the intensity of flowing current.

Additionally, as anticipated for the AC resistance, with measurements in time domain it is possible to verify the dependency on the instantaneous value of the underlying supply fundamental (Figure 9 of [29]). The internal inductance is heavily modulated by the bias point of the local hysteresis cycle, with a spread of values in the order of $50 \%$ for test signals of few $\mathrm{kHz}(3.5 \mathrm{kHz}$ in [29]), reduced to about $10 \%$ when going to $20 \mathrm{kHz}$ (where the magnetic permeability of the rail steel is much lower). The remarkable reduction of 
magnetic permeability is also confirmed by the reduction of an order of magnitude for the two values at $50 \mathrm{~Hz}$ and $10 \mathrm{kHz}$, measured with $10 \mathrm{~A}$ of current and reported in [24] as show in Table 3. For the temperature coefficient the same references in [24] may be used, with an average value of $0.25 \% /{ }^{\circ} \mathrm{C}$. No other references are available to author's knowledge.

Table 3. AC internal inductance values of running rails

\begin{tabular}{|c|c|c|c|c|}
\hline \multirow[t]{2}{*}{ Rail type } & \multirow[t]{2}{*}{ Rail weight $[\mathrm{kg} / \mathrm{m}]$} & \multicolumn{2}{|r|}{ Measured AC Inductance $[\mu \mathrm{H} / \mathrm{m}]$} & \multirow{2}{*}{ Ref. } \\
\hline & & Freq. $[\mathrm{Hz}]$ & Value vs. Current & \\
\hline - & 56 & $10,25,50,60$ & $0.58,0.46,0.29,0.29(50 \mathrm{~A}), 0.93,0.74,0.6,0.6(700 \mathrm{~A})$ & [3] \\
\hline - & - & 50 & $0.08(10 \mathrm{~A}), 0.21(400 \mathrm{~A}), 0.28(700 \mathrm{~A})$ & [24][33] \\
\hline - & - & 10000 & $2.02(10 \mathrm{~A})$ & [24][33] \\
\hline - & - & 25 & $0.48(200 \mathrm{~A}), 0.59(400 \mathrm{~A}), 0.61(600 \mathrm{~A}), 0.6(900 \mathrm{~A})$ & [27][32] \\
\hline - & - & 40 & $0.56(200 \mathrm{~A}), 0.67(400 \mathrm{~A}), 0.69(600 \mathrm{~A}), 0.67(900 \mathrm{~A})$ & [27][32] \\
\hline - & - & 60 & $0.64(200 \mathrm{~A}), 0.79(400 \mathrm{~A}), 0.83(600 \mathrm{~A}), 0.82(900 \mathrm{~A})$ & [27][32] \\
\hline - & - & 50 & $0.35(200 \mathrm{~A}), 0.43(400 \mathrm{~A}), 0.5(600 \mathrm{~A}), 0.51(1000 \mathrm{~A})$ & {$[27]^{(1)}$} \\
\hline - & - & 50 & $0.42(200 \mathrm{~A}), 0.57(400 \mathrm{~A}), 0.63(600 \mathrm{~A})$ & {$[27][34]^{(2)}$} \\
\hline UNI60 & - & 50 & $0.54(200 \mathrm{~A}), 0.66(400 \mathrm{~A}), 0.74(600 \mathrm{~A}), 0.77(1000 \mathrm{~A})$ & {$[27][28]^{(3)}$} \\
\hline UNI60 & - & 3500 & $0.19 \pm 25 \%(200 \mathrm{~A} @ 50 \mathrm{~Hz})$ & [29] \\
\hline UNI60 & - & 20000 & $0.167 \pm 5 \%(200 \mathrm{~A} @ 50 \mathrm{~Hz})$ & [29] \\
\hline
\end{tabular}

(1) Smallest ORE values, refs [6] and [7] in [18]

(2) Partial agreement with largest ORE values.

(3) Smallest values

\section{IMPACT OF THE RAIL PARAMETERS ON THE ELECTRIC INTERFACES}

Five main electrical interfaces were identified in the Introduction, for which the self impedance of running rails, and specifically the variability of rail resistance and inductance, play a role. Now these interfaces are discussed in more detail.

\subsection{Useful voltage and rail potential}

Limits for the useful voltage [1] and line voltage fluctuations under various traffic scenarios are always specified for the construction or upgrade of electric transportation systems, such as metros and light railways. Headway values and fleet composition are always quite demanding, so that relevant system parameters shall be accurately quantified for minimum uncertainty. Among them, rail resistance and $50 / 60 \mathrm{~Hz}$ impedance are particularly relevant for the longitudinal voltage drop along the return circuit, impacting also on the touch voltage of running rails and stray current.

Various simulation tools or simpler calculation sheets exist for the estimation of the useful line voltage and voltage drop along the return circuit. They go under the overall category of electromechanical simulation. By experience the assigned value for rail resistance is a more or less accurate $32-33 \mathrm{~m} \Omega / \mathrm{km}$, ignoring not only the variability due to temperature, but also that different samples of the same rail type do have different values of electrical resistance, $32-33 \mathrm{~m} \Omega / \mathrm{km}$ representing the minimum of measured values see Table 1 . There are cases where lower and difficult to actually maintain values are used in calculations, such as $20 \mathrm{~m} \Omega / \mathrm{km}$ [55] (curiously identical to the values assigned to the catenary system and to the stray current collector resistances) and $25.3 \mathrm{~m} \Omega / \mathrm{km}$ [56], Table 2 (together with apparently inconsistent values of the geometrical mean radius).

The rail internal resistance and inductance at 50/60 Hz are often "absorbed" within the loop impedance value assigned to the traction circuit, made of the catenary (or third rail) and the return circuit, when using single conductor models and approaches. Some simulators, however, give a complete representation of the traction system, where it is possible to distinguish between internal and geometrical inductance and assign independent dependencies on system parameters, soil resistivity and frequency [7, 57].

The assessment of the useful voltage available at the train pantograph or shoegear ensures that agreed performance is achievable. Due to the complexity of the scenario of an entire line with several rolling stock units in different operating conditions, the assessment is carried out by means of electromechanical simulations. Besides the internal voltage drops of supply substations, the voltage drops in the feeding system (catenary, third rail and other feeding conductors) and in the return circuit reduce the voltage fed and available to the trains. It may be said that especially in 3rd rail system (with a particularly low resistance of the feeding circuit), the longitudinal resistance of the return circuit is particularly important to limit system voltage drops. In low-voltage large-traffic systems (such as metros) the flowing current is in excess of several thousands Amps and feeding and return circuits must be optimized: a 10\% error in the estimate of the rail resistance causes a voltage drop of about $1.5 \mathrm{~V}$ per $\mathrm{km}$ per $\mathrm{kA}$ of flowing current, to compare with a margin of about $150 \mathrm{~V}$ between the substation output voltage and the average minimum acceptable line voltage. 
The error may increase if extreme temperature excursion is considered (rails under the sun in summer). The touch voltage (or touch potential) is a general concept, applicable in both steady (or normal) and transient (e.g. short circuit) conditions. It may be related to the conduction of current and the consequential voltage drop (as for the running rails themselves as part of the return circuit) or to inductive coupling onto conductive parts nearby.

The conductive voltage drop along the rails is the same already considered for the estimate of the useful voltage before in this section. For AC systems, rail impedance shall be considered, rather than simply DC resistance: it may be said that internal inductance adds to the self inductance and ignoring or underestimating it causes an underestimate, yet slight, of the voltage drop of the same order. Conversely, inductive touch voltage, occurring always for AC phenomena, is addressed in the "Induction on wayside conductive parts" section. Due to the safety relevance of touch voltage, the steady final value of the short circuit current is usually overestimated, so that the errors in the determination of the short circuit waveform amplitude and time constant considered in the next section are less critical.

\subsection{Short circuit calculation and transient behavior}

A few works have accurately investigated the short-circuit behavior of DC railway systems with rectifier substations for remote faults, when the track impedance is a significant element of the fault circuit. In [2] the authors underline that the rails account for the $25 \%$ of the total fault impedance and that their internal inductance and resistance vary during the transient, as a function of the instantaneous frequency (due to skin effect) and current amplitude (going towards saturation). The DC resistance influences the steady state final value of the short-circuit current waveform, whereas inductance and resistance change dynamically, and so their ratio (the time constant), during the transient (mainly during the initial rise time). Time constant values estimated from experimental data [2] varied by a factor of 5 to 8 for short circuits recorded at Hong Kong MTRC and London Docklands. This is in agreement with the variability of internal resistance and inductance reported in the previous section. The relevance of the accurate prediction of the initial short-circuit current transient resides especially in the estimation of the time derivative of the current, sensed by modern protection relays to implement High Speed Circuit Breakers suitable for the very large short circuit current of metros.

\subsection{Induction on wayside conductive parts}

Induction on longitudinal conductive parts is caused by the traction current and its AC components [5]. In principle the main inducing loop is formed by the catenary (or third rail) and the return circuit (first of all the running rails); in general all conductors carrying supply or return current exert inducing effects, as a function of mutual coupling with the victim circuit. The amount of return current flowing in the running rails, if not dispersed in the soil, reduces the area of the inducing loop, reducing proportionally the induced voltage. In general, the current distribution among return circuit conductors is influenced by the mutual inductance terms and the rail internal impedance shall be considered especially when return conductors are quite close to the victim conductor (e.g. a cableway), so that also proximity effect plays a role for accurate results.

Although the equations for the calculation of induced induction shown in [5] suggest a simplified approach that does not need this level of detail, the accurate calculation of the screening coefficients for return rail (RR) and return conductor (RC) systems, possibly equipped with booster transformers (BT-RC), require the inclusion of a full characterization of the running rails: [5], sec. IV.B, and [23], page 433-437.

In general, a screening coefficient is defined (notation as in [5]): $k_{l b}=1-Z_{c r} / Z_{r r}$, where $Z_{c r}$ is the mutual impedance between the catenary and the return circuit, and $Z_{r r}$ is the self impedance of the return circuit. The latter self term includes the rail internal inductance, which especially at low power frequency accounts for a significant fraction. Changes of more than 2:1 result from the modeling (Figures 14 and 15 in [24]) for frequencies up to $50 \mathrm{~Hz}$ and variable flowing current up to $1000 \mathrm{~A}$. It is observed that the internal impedance always adds to $Z_{r r}$, so to increase $k_{l b}$, or in other words to reduce the screening effect. Based on the experimental values shown in Table 2 and 3, compared to the calculated mutual and external self inductance as in (1), the expected increase of $k_{l b}$ at $50 \mathrm{~Hz}$ is between 50 and $65 \%$, so that the $k_{l b}=0.51$ given in [5], sec. IV.B, increase to $0.76-0.84$.

It is easy to see that the rail resistance and its uncertainty do not play a role in the accurate determination of the screening coefficients; significant errors in the resistive terms are well masked by external reactance terms. For the determination of the source current, steady state values are obtained by extrapolation to worst-case scenarios (such as overloading) or from electromechanical simulations. Short circuit current is usually estimated considering a short circuit at variable distance from the substation, with decreasing current intensity with length, but increasing length of the inducing loop. 


\subsection{Stray current}

Stray current may be estimated when calculating the rail voltage along the line for system sizing in section "Useful voltage and rail potential", e.g. by means of electromechanical simulations [7].

The role of the rail longitudinal resistance is manifold:

- Determination of the rail touch voltage during simulation;

- Calculation of pulled vehicle current, also using the simplified model proposed in [8]: (5), (6) and the propagation constant parameter $\gamma$ all depend on the rail resistance; realistic values of 35 and 36 $\mathrm{m} \omega / \mathrm{km}$ were used in $[8,10]$, that match well an estimate based on Table 1 and include welding of rail segments and, in case of Dubai [8], the higher environmental temperature;

- Assessment of the efficiency of the stray current capturing system.

Modern systems are protected by specific rebars underneath the running rails forming the "stray current mat" and bonded to the stray current collector cable wayside, in parallel to the running rails, draining the stray current back to the substation. The efficiency $E$ [58], (3), can be expressed as the ratio of the captured stray current flowing in the mat $\left(I_{m a t}\right)$ and the stray current leaving the rail $\left(I_{\text {leak }}\right)$ :

$$
E=\frac{I_{\text {mat }}}{I_{\text {leak }}}
$$

Efficiency can be also readily related to the ratio of the longitudinal resistance of the rails and the transversal resistance between the rebars and the earth for the protected track section length, then combined with the stray current collector resistance once bonded to it $[7,9,11]$. Since the further leakage from the stray current mat to the structure and the earth cannot be reduced at will due to the significant conductivity of concrete (especially in humid places, including tunnels), reducing the longitudinal rail resistance (including the contribution of welding, fishplates and bonding) is an important degree of freedom left to the designer. The observed variability of more than $10 \%$ in electrical resistance of rail samples of the same type has a direct impact of the same entity on the resulting efficiency of the stray current collection system. Additionally, measurement of track insulation using method A.2 of EN 50122-2 [48], makes use of rail resistance to estimate rail current with a simpler rail voltage drop measurement. Rail resistance thus has a direct influence on the assessment of track insulation and shall be measured by means of method A.1.

\subsection{Track circuits}

Internal inductance and AC resistance may be considered relevant for accurate tuning of track circuits at audio-frequency. Tuning is a sensitive operation, in most cases consisting in the identification of one of the resonance humps of the capacitively compensated track. For receivers adopting frequency shift keying (FSK) modulation, balancing of the two FSK channel is the objective [12]; alternatively the maximization of the transmitter current coupled onto the track is another criterion.

The compensated track has a transfer function characterized by a sequence of peaks and valleys of the receiver voltage as shown in Figure 1, changes to rail internal inductance and resistance may lead to changes of the values of the peak amplitude and the factor of merit, causing slight detuning, that implies a worse signal-to-noise ratio or lower sensitivity with respect to shunting axle resistance and track leakage to earth (the so called "ballast resistance"). Implications for track circuit performance and functional safety aspects (e.g. probability of detection and Right or Wrong Side Failure events) are evident. Such variability should be taken into account during design and by the tuning procedure, although the influence of the traction current amplitude is only estimated, but most of the time neglected, since tuning is performed without traffic.

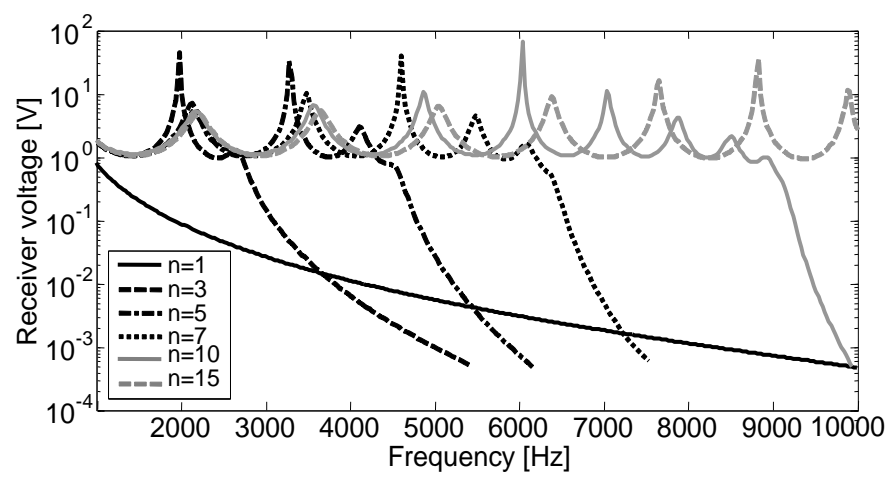

Figure 1. Receiver voltage for increasing number of resonant cells along the track 
Modern track circuits feature the monitoring of internal quantities, in particular the received voltage for the two FSK frequencies and the dynamic range between free and occupied track conditions. The validated tool for track circuit simulation and tuning presented in [12] allows sensitivity and worst-case analysis for all these factors. In the specific case the variability of the AC rail resistance $(1 \mathrm{~m}$ of rail is equivalent to the resistance of the S-bond as per Table 1 in [12]) was mitigated by increasing artificially the resistance of the S-bond, with the advantage of a more stable transfer function and a lower factor of merit, so a wider resonance peak with less steep shoulders, implying an easier tuning. In general the variability of track parameters, and in particular of rail longitudinal parameters, is relevant for track circuit operation [13-19].

For axle counters the change of the current distribution with frequency inside the rail and its impact on sensitivity and susceptibility of the axle counter head is taken into account experimentally and conveyed in the susceptibility levels indicated in the EN 50238-3 [59]. It is however worth noting that, as introduced in sec. 0 , the distribution of the current and of the magnetic field inside the rail depends on the local permeability value, both in terms of absolute value and regarding the differential hysteresis cycles [28, 29], as well as proximity effects. For the latter it is thus important to include prescriptions for the minimum separation distance of current carrying conductors. To conclude, the model of the overall magnetic circuit including the rail and the moving wheel is extensively considered by manufacturers, in order to specify construction and installation tolerances, besides the optimization of the detection circuit and working frequency.

\section{CONCLUSION}

This work has presented and discussed the sources for experimental values of DC and AC resistance and internal inductance of running rails. Despite their relevance as the interface element in all guide way transportation systems, running rails are seldom characterized for their electrical characteristics. Their electric behavior is relevant for some electric interfaces and phenomena, such as useful voltage determination, variability of rise time of short-circuit waveforms, stray current, track circuit modeling and tuning. There are situations in which complete, accurate and reliable models and calculations are necessary, mostly for exigencies of system assurance, safety demonstration and performance assessment. This implies being able to include variability of parameters (including rail electrical parameters) in a final compliance statement (examples have been given in the Introduction of validation of simulation models and tuning of a circuit model electric arc response prediction). This work thus has organized and discussed the relevance of the running rails for a set of electrical interfaces of a modern electric transportation system (useful voltage, touch voltage, transient short circuit behavior, stray current and track circuits tuning and analysis) relevant to EMC, system operation and performance, and safety.

\section{REFERENCES}

[1] CENELEC EN 50388, "Railway Applications - Power supply and rolling stock - Technical criteria for the coordination between power supply (substation) and rolling stock to achieve interoperability," IEC Std 62313, 2012.

[2] J. C. Brown, J. Allan, and B. Mellitt, "Calculation of remote short circuit fault currents for DC railways," IEE Proceedings B (Electric Power Applications), vol. 139, no. 4, pp. 289-294, 1992.

[3] J. C. Brown, J. Allan, B. Mellitt, "Calculation and measurement of rail impedances applicable to remote short circuit fault currents," IEE Proceedings B (Electric Power Applications), vol. 139, no. 4, pp. 295-302, 1992.

[4] C. L. Pires, S. I. Nabeta, J. R. Cardoso, "Second-order model for remote and close-up short-circuit faults currents on DC traction supply," IET Power Electronics, vol. 1, no. 3, pp. 348-355, Mar. 2008.

[5] A. Mariscotti, "Induced voltage calculation in electric traction systems: simplified methods, screening factors and accuracy," IEEE Transactions on intelligent transportation systems, vol. 12, no. 1, pp. 201-210, Mar. 2011.

[6] J. Bongiorno, G. Boschetti and A. Mariscotti, "Low-frequency coupling: Phenomena in electric transportation systems," IEEE Electrification Magazine, vol. 4, no. 3, pp. 15-22, Sep. 2016.

[7] A. Ogunsola, L. Sandrolini and A. Mariscotti, "Evaluation of stray current from a dc electrified railway with integrated electric-electromechanical modeling and traffic simulation," IEEE Transactions on Industry Applications, vol. 51, no. 6, pp. 5431-5441, Nov. 2015.

[8] A. Ogunsola, A. Mariscotti and L. Sandrolini, "Estimation of Stray Current from a DC Electrified Railway and Impressed Potential on a Buried Pipe," IEEE Transactions on Power Delivery, vol. 27, no. 4, pp. 2238-2246, Oct. 2012.

[9] I. Cotton, C. Charalambous, P. Aylott and P. Ernst, "Stray Current Control in DC Mass Transit Systems," IEEE Transactions on Vehicular Technology, vol. 54, no. 2, pp. 722-730, Mar. 2005.

[10] A. Zaboli, B. Vahidi, S. Yousefi and M. M. Hosseini-Biyouki, "Evaluation and Control of Stray Current in DCElectrified Railway Systems," IEEE Transactions on Vehicular Technology, vol. 66, no. 2, pp. 974-980, Apr. 2016. 
[11] A. Mariscotti, A. Ogunsola, U. Reggiani and L. Sandrolini, "Mitigation of electromagnetic interference generated by stray current from a dc rail traction system," International Symposium on Electromagnetic Compatibility-EMC EUROPE, 2012,

[12] A. Mariscotti, M. Ruscelli, M. Vanti, "Modeling of audiofrequency track circuits for validation, tuning and conducted interference prediction," IEEE transactions on intelligent transportation systems, vol. 11, no. 1, pp. 52-60, Mar. 2011.

[13] G. D'Addio, P. Ferrari, A. Mariscotti, P. Pozzobon, "Integrated modelling of audiofrequency track circuits," IEE EMC York 99, 1999.

[14] A. Szeląg, "Rail track as a lossy transmission line. Part I: Parameters and new measurement methods," Archives of Electrical Engineering, vol. 49, no. 3-4, pp. 407-423, 2000.

[15] A. Szeląg, "Rail track as a lossy transmission line. Part II: New method of measurements-simulation and in situ measurements," Archives of Electrical Engineering, vol. 49, no. 3-4, pp. 425-453, 2000.

[16] F. Espinosa et al., "Detector of Electrical Discontinuity of Rails in Double-Track Railway Lines: Electronic System and Measurement Methodology," IEEE Transactions on Intelligent Transportation Systems, vol. 18, no. 4, pp. 743-755, Apr. 2017

[17] X. Zhou, Z. Wang, and Z. Liu, "Study on the effect of compensation capacitors on broken rail detection in audiofrequency track circuits," IEEE International Conference on Intelligent Rail Transportation (ICIRT), pp. 284-287, 2016.

[18] S. Ciurlo and A. Mariscotti, "Track compensation with Audiofrequency Track Circuits," Proc. of the Intern. Conf. on Electrical Systems for Aircraft, Railway and Ship Propulsion (ESARS), 2010.

[19] L. Ivanek, V. Mostyn, K. Schee, and J. Grun, "The Sensitivity of the Input Impedance Parameters of Track Circuits to Changes in the Parameters of the Track," Advances Electr. and Electron. Eng., vol. 15, no. 1, pp. 77-83, 2017.

[20] J. Bongiorno and A. Mariscotti, "Evaluation of performances of indexes used for validation of simulation models based on real cases," International Journal of Mathematical Models and Methods in Applied Sciences, vol. 9, pp. 29-43, 2015.

[21] G. Crotti, et al., "Pantograph-to-OHL Arc: Conducted Effects in DC Railway Supply System," IEEE Transactions on Instrumentation and Measurement, vol. 68, no. 10, pp. 3861-3870, oct. 2019.

[22] G. Crotti, et al., "Pantograph-to-OHL Arc: Conducted Effects in DC Railway Supply System," IEEE 9th Intern. Workshop on Applied Meas. for Pow. Sys. (AMPS), Sep. 2018.

[23] CCITT, "Directives concerning the protection of telecommunication lines against harmful effects from electric power and electrified railway lines-Volume II," Geneva, Switzerland, 1989.

[24] R. J. Hill, S. Brillante, P. J. Leonard, "Railway track transmission line parameters from finite element field modelling: series impedance," IEE Proceedings-Electric Power Applications, vol. 146, no. 6, pp. 647-660, Dec. 1999.

[25] G. D'Addio, M. Fracchia, A. Mariscotti and P. Pozzobon, "Sensitivity analysis of railway line impedance to variations of electrical and geometrical parameters," World Congress on Railway Res. WCRR, 1999.

[26] R. Garg, P. Mahajan and P. Kumar, "Sensitivity Analysis of Characteristic Parameters of Railway Electric Traction System," International Journal of Electronics and Electrical Engineering (IJECE), vol. 2, no. 1, pp. 8-14, 2014.

[27] A. Mariscotti and P. Pozzobon, "Resistance and internal inductance of traction rails: A survey," IEEE Transactions on Vehicular Technology, vol. 53, no. 4, pp. 1069-1075, 2004.

[28] A. Mariscotti and P. Pozzobon, "Measurement of the Internal Impedance of traction rails at $50 \mathrm{~Hz}$," IEEE transactions on instrumentation and measurement, vol. 49, no. 2, pp. 294-299, Apr. 2000.

[29] A. Mariscotti and P. Pozzobon, "Measurement of the internal impedance of traction rails at audiofrequency," IEEE Transactions on Instrumentation and Measurement, vol. 53, no. 3, pp. 792-797, Jul. 2004.

[30] F. Filippone, A. Mariscotti and P. Pozzobon, "The Internal Impedance of traction rails for dc railways in the 1-100 kHz frequency range," IEEE Transactions on Instrumentation and Measurement, vol. 55, no. 5, pp. 1616-1619, Oct. 2006

[31] E. Kennelly, F. H. Achard, S. Dana, "Experimental researches on the skin effect in steel rails," Journal of Franklin Institute, 1916.

[32] H. M. Trueblood, G. Wascheck, "Investigation of rail impedances," Electrical Engineering, pp. 898-907, 1933.

[33] F. R. Holmstrom, "The model of conductive interference in rapid transit signaling system," IEEE transactions on industry applications., vol. 22, no. 4, pp. 756-762, 1986.

[34] R. J. Hill, and D. C. Carpenter, "Determination of rail internal impedance for electric railway traction system simulation," IEE proceedings B-electric power applications, vol. 138, no. 6, pp. 311-321, Nov. 1991.

[35] A. Mariscotti, P. Pozzobon, M. Vanti, "Simplified modelling of $2 \times 25 \mathrm{kV}$ AT Railway System for the solution of low frequency and large scale problems," IEEE Trans. Pow. Del., vol. 22, no. 1, pp. 296-301, Jan. 2007.

[36] A. Mariscotti, "On the common mode to differential mode transformation of conducted disturbance in double track traction lines," IEEE Intern. Conf. on Electrical Systems for Aircraft, Railways and Ships (ESARS), 2012.

[37] D. C. Carpenter and R. J. Hill, "Railroad Track Electrical Impedance and Adjacent Track Crosstalk Modeling Using the Finite-Element Method of Electromagnetic Systems Analysis," IEEE transactions on vehicular technology, vol. 42, no. 4, pp. 555-562, Nov. 1993.

[38] A. Mariscotti, "Self and mutual capacitance of conductors in air and lossy earth with application to electrified railways," Archives of Electrical Engineering, vol. 68, no. 4, pp. 859-873, 2019.

[39] A. Mariscotti and P. Pozzobon, "Experimental results on low rail-to-rail conductance values," IEEE transactions on vehicular technology., vol. 54 no. 3, pp. 1219-1222, May 2005,.

[40] G. Lucca, "Evaluation of Rail Conductances,” Ingegneria Ferroviaria, vol. 12, pp. 935-949, Dec. 2017. 
[41] G. Lucca, "Simplified Analytical Method for Evaluating Rails Conductance," Ingegneria Ferroviaria, vol. 4, pp. 249-263, Apr. 2020.

[42] EN 13674-1, “Railway applications - Track - Rail - Part 1: Vignole railway rails 46 kg/m and above,” 2017.

[43] F. Kiessling, R. Puschmann, A. Schmieder and E. Schneider, "Contact Lines for Electric Railways: Planning, Design, Implementation, Maintenance, Siemens," Publicis Corporate Publishing, 2009.

[44] V. Koláŕ, P. Bojko and R. Hrbáč, "Measurement of current flowing through a rail with the use of Ohm's method; determination of the impedance of a rail," Przeglad Elektrotechniczny, vol. 89, no. 6, pp. 118-120, 2013.

[45] Nippon Steel and Sumitomo Metal, "Rails," NSSMC, 2014. [Online], Available: https://www.nssmc.com/product/catalog_download/pdf/K003en.pdf.

[46] E. Szychta, L. Szychta, M. Luft and K. Kiraga, "Application of 3D Simulation Methods to the Process of Induction Heating of Rail Turnouts," Infrastructure Design, Signalling and Security in Railway, 2012.

[47] SPG 0709, "Traction return, track circuits and bonding," NSW Transport Rail Corp., 2017. [Online]. Available: www.transport.nsw.gov.au/system/files/media/asa_standards/2017/spg-0709.pdf

[48] CENELEC EN 50122-2, "Railway applications - Fixed installations - Electrical safety, earthing and the return circuit - Part 2: Provisions against the effects of stray currents caused by dc traction systems," 2010.

[49] M. Zagirnyak, V. Prus, D. Rodkin, Y. Zachepa and V. Chenchevoi, "A refined method for the calculation of steel losses at alternating current," Archives of Electrical Engineering, vol. 68, no. 2, pp. 295-308, 2019.

[50] M. Mirzaei and P. Ripka, "Analysis of Material Effect on Rail Impedance," 53rd International Universities Power Engineering Conference, 2018.

[51] A. Dolara and S. Leva, "Calculation of Rail Internal Impedance by Using Finite Elements Methods and Complex Magnetic Permeability," International Journal of Vehicular Technology, vol. 2009, 2009.

[52] L. Di Rienzo, Z. Zhang, and S. A. Pignari, "Boundary-element computation of per-unit-length series parameters of railway lines," IEEE Transactions on Electromagnetic Compatibility, vol. 51, no. 3, pp. 825-832, Aug. 2009.

[53] M. N. Saravana Kumar and R. Murugna, "Analysis of Inductance Gradient and Current Density Distribution Over Different Cross-section of Rails," International Journal of Electrical and Computer Engineering (IJECE), vol. 8, no. 2, pp. 723-729, Apr. 2018.

[54] K. Kiraga and E. Szychta, "Research of selected electric and magnetic properties of railway rail," Archives of Electrical Engineering, vol. 61, no 3, pp. 347-357, Sep. 2012.

[55] G. Du, D. Zhang, G. Li, C. Wang, and J. Liu, "Evaluation of Rail Potential Based on Power Distribution in DC Traction Power Systems," Energies, vol. 9, no. 9, Sept. 2016.

[56] T. H. Chen and R. N. Liao, "Modelling, simulation, and verification for detailed short-circuit analysis of a $1 \times 25 \mathrm{kV}$ railway traction system," IET Generation, Transmission \& Distribution, vol. 10, no. 5, pp. 1124-1135, Oct. 2016.

[57] V. I. Havryliuk, "Modeling of the traction current harmonics distribution in rails," Електромагнітна сумісність та безпека на залізничному транспорті (Electromagnetic compatibility and railway safety), no. 13, pp. 20-27, 2017.

[58] F. Fichera, A. Mariscotti, A. Ogunsola, "Evaluating Stray Current from DC Electrified Transit Systems with Lumped Parameter and Multi-Layer Soil Models," Proc. of 15th IEEE Region 8 EuroCon 2013 Conf., July, 2013.

[59] CENELEC CLC/TS 50238-3, "Railway applications - Compatibility between rolling stock and train detection systems - Part 3: Compatibility with axle counters," 2015.

\section{BIOGRAPHY OF AUTHOR}

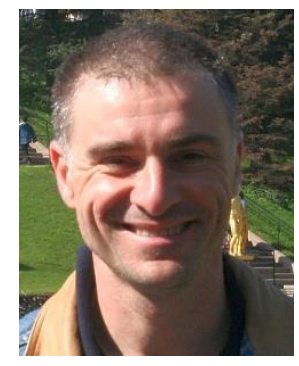

Andrea Mariscotti degreed in Electronic Eng. in 1991 (cum laude) and the Ph.D. in Electrical Eng. in 1997 from the University of Genova. As a Tenure researcher under different grants between 1998 and 2004 he worked in national and international research programs. In 2005 he became Assistant Professor at the former Electrical Eng. Dept. of the University of Genova. His main research interests are EMC and Power Quality applied to industrial, military and transportation systems, modeling and measurement of electromagnetic interference, and its relevance to safety and availability. He is also active in the field of electrical safety, earthing and bonding and stray current protection applied to transportation systems. He is Member of the IEEE I\&M Society and of the Italian Electrical and Electronic Measurement Group (GMEE); he is also a reviewer for IEEE, Elsevier, Institute of Physics, MDPI and Springer. 